\title{
Gestures and the Spoken Language: A Crucial Semiotic and Symbiotic Relationship in Multilingual Mathematics Classes
}

\author{
Clemence Chikiwa ${ }^{1 *}$ \\ ${ }^{1}$ Rhodes University, SOUTH AFRICA
}

Received 24 May $2021 \cdot$ Accepted 30 July 2021

\begin{abstract}
This study's focus was two-fold, first to look at forms of gestures teachers of multilingual mathematics classes use during teaching; and second to find out how teachers of multilingual mathematics classes utilize learners' home language, language of learning and teaching and gestures to foster understanding in the teaching of mathematics. This qualitative case study is informed by the embodied cognition theory and social constructivism. Two purposively selected Grade 11 teachers were observed and video recorded while teaching trigonometry for a week in a multilingual policy environment. They were each interviewed for an hour. Results shows that iconic and deictic gestures were frequently used to link the teacher's verbal language and the diagrams on the chalkboard or what was previously learnt, to ground cognition into the physical teaching and learning environment. Metaphoric gestures were less used while beat gestures were not used. Results also show that there exists an intricate semiotic and symbiotic relationship between gestures (bodily actions), and spoken language (in two or more languages in the same environment). In this paper, I conclude that in multilingual classes all forms of teacher gestures that indicate and refers to objects and locations in reality may help improve learning. Gestures and verbal languages complement each other, and should be used as resources for mediating and scaffolding teaching and learning.
\end{abstract}

Keywords: gestures, multilingual, language, teaching, mathematics

\section{INTRODUCTION}

This paper focusses on the nature of gestures used and how they were used by the selected teachers during their teaching of multilingual mathematics classes to provide access to mathematics concepts. Although the South African language policy (SALP) and the language in education policy (LiEP) of 1997 refers to multilingualism, they do not provide explicit support for the strategic planning and execution of other possible language practices, particularly for an educational setting. Such practices include code switching, code mixing, code meshing, translanguaging and gestures among others. Interest was specifically with those gestures that accompanied teachers' use of learners' first language through code switching.

Adler (2001) defines code switching as the concurrent use of two or more languages in one conversation. In the literature, 'code-switching' or 'language alternation' is also referred to as code meshing, code mixing, 'language mixing' (Redlinger \& Park, 1980), and 'code-alternation' (Auer, 1984). Ho (2007) explains code mixing from a linguist's perspective as referring to "any mixture of linguistic elements of two or more language systems in the same utterance at various levels: phonological, lexical, grammatical and orthographical" (p. 2). Code meshing is the act of combining local, vernacular, colloquial, and world dialects of English on formal assignments and in everyday conversation, in an attempt to embrace the diverse world in which we reside (Young et al., 2014). Code meshing as well as code mixing embraces people's cultural differences and allows them to authentically illuminate their personality.

Other researchers such as Creese and Blackledge (2010) have employed the term 'translanguaging' to depict language fluidity and movements during teaching. Canagarajah (2011, p. 40) defines translanguaging as "the ability of multilingual speakers

(c) 2021 by the authors; licensee Modestum. This article is an open access article distributed under the terms and conditions of the Creative Commons Attribution License (http://creativecommons.org/licenses/by/4.0/).

\ clemence.chikiwa@gmail.com (*Correspondence) 


\section{Contribution to the literature}

- South Africa and many other parts of the world are faced with language related challenges. This paper contributes to the on-going language debate in multilingual teaching environments.

- There is a dearth of research in South Africa that explores and exemplifies the crucial symbiotic relationship between gestures and spoken language for teaching purposes. This study had endeavored to awaken the need for further research in this area.

- Teaching of multilingual classes especially of mathematics is met with various challenges. This study provides possible ways in which teachers can utilize language in its various forms to further the teaching of mathematics.

to shuttle between languages, treating the diverse languages that form their repertoire as an integrated system". With translanguaging, the mind is seen as an integrated whole, in which the person doesn't really separate different languages they know and use or different modalities whether written, oral or kinesthetic to communicate with others or when drawing meaning from multilingual and multimodal input (García, 2009; Li, 2017). Code switching, code meshing, code mixing and translanguaging are similar to each other in that they all refer to multilingual speakers' shuttling between languages in a natural manner for communication during a conversation. All these four processes involve use of multiple discursive practices, where teachers and their learners incorporate the language practices of school into their own linguistic repertoire freely and flexibly for enhancing communication. The definitions of code mixing, code meshing and translanguaging are closely related to code switching. In this study I will not distinguish between these forms of language alternations. I will refer to all these as code switching.

During teaching of STEM subjects, using a poorly mastered language of learning and teaching (LOLT) can be a challenging task (Kotzé, Van der Westhuizen, \& Barnard, 2017). Mathematics teachers in their efforts to make the subject content accessible to learners in multilingual classes use a variety of language practices (Alibali \&Nathan, 2012). These include simultaneous use of learners' first language and the LOLT. This can be done with use of gestures to accompany the spoken language (Alibali \& Nathan, 2012). The focus of this paper is on an analysis of how selected Grade 11 teachers make use of gestures in conjunction with their spoken language when teaching mathematics in a multilingual policy environment. In a previous study, which led to the observations for this paper, I noticed that when mathematics teachers switched their language of instruction to the first language of the learners and the teachers, this switch was accompanied by gesturing and other bodily actions, to not only attract and sustain the attention of their learners, but also to communicate mathematically (Chikiwa \& Schäfer, 2019). I argue that this gesturing is a crucial element in the teaching process, and ultimately in the learning process of multilingual learners. I observed that there exists an intricate semiotic and symbiotic relationship between these gestures, and the spoken language (in two or more languages in the same environment), and thus argue that even though the policy is not explicit on their use, gestures can provide important and helpful tools to support multilingual teaching, if used appropriately. These gesturing tools may be used as mediation tools to visualise mathematics, ground mathematics concepts to a referent, or build a mathematical concept, or simply to complement the spoken language. The following research questions guided this study:

What forms of gestures do teachers of multilingual mathematics classes use during teaching?

How do teachers of multilingual mathematics classes utilize learners' home language, language of learning and teaching (LOLT,) and gestures to foster understanding in mathematics?

\section{CONCEPTUAL FRAMING OF THE STUDY}

In this paper, I focus on the language in education context of South Africa, gestures and their classification together with multilingualism as key conceptual aspects for this study.

\section{The South African Language in Education Context}

The constitution of South Africa and the current language policies aim to provide and promote a multilingual environment in the country (Mkhize \& Balfour, 2017). This is because multilingualism is viewed as a resource that the country must utilize (Setati, 2008), and every institution should take advantage of. The actualisation and realisation of the constitutional right to true multilingual education in South Africa's secondary schools is being promoted, though it remains controversial. According to Census of 2011 done by Statistics South Africa the majority of people in South Africa speak languages other than English and Afrikaans which were the only official languages for the country prior to 1994, yet secondary school education is dominated by these two to this day. As per the Language in Education Policy (LiEP) of 1997 in South Africa, there is nothing preventing schools from choosing an African language as the language of learning and teaching (LOLT) at all levels of school education. Other factors 
tied to historical, socio-political and economic factors in the country seem to take precedence over educational considerations of the effects of what language to use as the LOLT in schools. This has led to the continued hegemony of English and Afrikaans resulting in undermining the language rights of many learners as enshrined in the LiEP and the constitution of South Africa (Figone, 2012; Setati, 2008).

In an address by the then Minister of Education, Naledi Pandor, at a language colloquium in Cape Town (September 2006), she said that LiEP should be shaped in a manner that promotes the achievement of three important imperatives:

1. increased use of and competence in the mother tongue, as a medium of instruction, at least in primary school,

2. improved ability in a second language, such as English, to support further study and respond to the legitimate desires of parents and learners, and

3. the development of communicative ability in at least one African language, for all South African children.

None of these imperatives are related to teaching and/or learning and using these languages to acquire content knowledge in STEM subjects. They are more on language learning and development but do not specifically refer to the learning of STEM subjects like mathematics.

The language complexities and associated dilemmas in South African directly affects schools (Probyn, 2009) and hence the education system of the country. While each province has a dominant language, there exist in many communities the presence of other languages in varying proportions. Such a presence is not easy to deal with for many schools. The resulting complexities associated with multilingual situations are unfairly left for individual schools and their communities to deal with (Figone, 2012; Probyn, 2009; Setati, 2008). Such complexities inter alia relate to the dilemmas associated with which language to use as the LOLT in the particular school. This in many cases forces the School Governing Boards (SGBs) of such schools to simply opt for English as the LOLT, even if the majority of learners are still not proficient in that language. These complexities have resulted in teachers finding and developing their own language practices to ensure that teaching and learning of STEM subjects still provides access to knowledge for these learners. Such methods include code switching, code mixing, code meshing and translanguaging as discussed above in this paper.

In South Africa, learners are taught in the LOLT that they are still learning and hence in many cases may not understand. One issue affecting South Africa, especially with the LiEP policy has been "the extent and nature of support that second language learners require to succeed academically. Students must learn the language of instruction at the same time as they are expected to learn academic content through the language of instruction" (Cummins, 2000, p. 57). In many South African public schools, learners are forced to learn in a LOLT (English in most cases) that they are not proficient in. This is because most schools have chosen an LOLT that is less familiar to learners and that they are still learning. Such a scenario has, and still is, forcing teachers of content subjects like mathematics to teach both English and mathematics (Probyn, 2009). This leaves teachers with pedagogical dilemmas as they teach learners of content subjects like mathematics in a language that they mostly do not understand. It is interesting to note that one of the reasons why the teaching and learning in an unfamiliar language still exits, is because a large proportion of people in many parts of South Africa have a strong belief that the best way to learn a foreign language (in this case, English) is to have it as a LOLT (Figone, 2012). This is coupled by many parents' quest for their children to learn and be taught in English as they associate it as a language of power and of access to economic goods (Setati, 2008). Thus, I submit that the implementation of the LiEP policy in South Africa's secondary school STEM subjects teaching is associated with increasing problems and complexities.

Because of the hegemony of English and its prevalent use as the LOLT in many public schools in South Africa (Figone, 2012), the influences from parents through SGBs, coupled with learners' low proficiency in this language, teachers have been forced to find other coping language practices. The use of code switching, code mixing, code meshing and translanguaging together with gestures has thus become of paramount importance in mathematics classes in secondary schools. Teachers use various semiotics resources such as material objects, speech in different languages and gestures in the teaching of mathematics in the classroom (Arzarello et al., 2009). This is particularly important and useful in multilingual classrooms as it utilise the visual and the verbal processes to create meaning in the teaching of mathematics (Borodo, 2015). In this paper, I thus argue that gestures as visual cues and a language in its own right can be exploited in multilingual contexts as an expressive and effective means to convey mathematical concepts.

In the teaching of mathematics, teachers routinely and regularly produce gestures along with their speech which, I argue have the potential to influence pupils' learning. Research has shown that the combination of teachers' speech and gesture often provides greater insight into learners' mathematical knowledge and understanding than either words or gestures alone (McNeill, 1992; Sabena, 2018). This access to knowledge and understanding that gestures may enable, is necessary in multilingual classes, where the LOLT is neither the teacher's nor the learners' first. In this study, I define gestures as a multiplicity of spontaneous 
movements of the arms and hands closely synchronized and generated as part of the process of speaking (McNeill, 1992).

\section{Gestures and Multilingual Mathematics Classroom Teaching}

Studies in multilingual settings have shown that in situations where the LOLT is the second or third language of the learners, teachers often use the first language of these learners as a resource to aid understanding. This is often done through teacher code switching accompanied by gestures. McNeill (1992) posited that, "gestures are an integral part of language as much as are words, phrases and sentences" (p. 2). My focus on teachers' gestures is informed by the large body of research showing that gestures contribute to communication in a wide range of settings (Kendon, 2004; Sabena, 2018). The use of visualization processes such as gestures in teaching mathematics is an important component to help learners to build their own adequate internal representations of mathematical ideas. Gestures help to make visible the mental pictures of concepts. I submit that such use of gestures is particularly relevant in multilingual classes to aid understanding.

Several studies have pointed towards the importance of gestures' ability to communicate the visual appearance of mathematical objects, such as shapes and slopes on line graphs (Sabena, 2018; Yoon, Thomas, \& Dreyfus, 2011). Gestures are hence crucial for communicating and constructing mathematical understanding (Yoon et al., 2011) especially in situations where learners are not proficient in the LOLT. Thus, gesturing, as well as drawings and pictures have the potential to play a mediating role in the visualisation of ideas and concepts in relation to teachers explaining concepts to learners in multilingual settings (Kendon, 2004). Work by Alibali et al. (2013), and that of Hare and Sinclair (2015) suggest that a combination of gestures and diagrams provides real-time evidence of the meanings that gesturing and diagramming help to create in mathematics.

Gestures have been found to play a key role in the thinking process and in aiding conceptual learning (Goldin-Meadow \& Alibali, 2013; Roth, 2001) of content subjects such as mathematics. Hence as noted by McNeil (1992), gestures are useful in cognitive development. This according to researchers (Edwards, 2009; McNeil, 1992, 2005; Kendon, 2004), is evidenced by learners' language acquisition where gestures and speech develop together. Alibali and Nathan (2012) emphasize that gestures are crucial during learning because they ground concepts through acts such as pointing, representing and writing. As a result, gestures promote the concretisation of concepts taught by referring to the actual physical referent.
McNeill (1992) mentions that "gestures do not just reflect thought but have an impact on thought. Gestures, together with language, help constitute thought" (p. 242). Thus, gestures may reflect both what the teachers' thoughts about his/her learners at a particular moment are, and what the learners themselves may be struggling with at that same moment. Goldin-Meadow and Alibali (2013) raises another important point that "gesture can change speakers' thoughts" (p. 247). When teachers use gestures appropriately in teaching mathematics, the process has the potential to change the teacher's thinking about the concepts he/she is referring to, and this may result in this same speaker altering or revising the course of thinking and learning. Such refinements are vital for making conceptual learning possible during teaching.

In their investigation of gestures, Yoon et al., (2011) used the 'grounded blends' theory which explores how individuals employ gestures to construct and communicate mathematical concepts and understanding through what they have called 'a physical gesture space'. They illustrated in their study how gestures and the physical mathematical gesture space work as semiotic resources for mathematical learning. During teaching, gestures may be used to anchor various configurations of mathematical concepts to some spatial layout and destinations with deictic gestures pointing into the empty gestural space (Yoon et al., 2011). This is considered a common practice which can aid the teaching and learning of mathematics. Relating gesture space to learning, Hutchins and Palen (1997, p. 23) states that "gestures and the space inhabited by speakers and listeners are normally thought of as providing context for the interpretation of speech." The advantage of gestures and mathematics gesture spaces as noted by Yoon et al. (2011), is their ability to assist learners to move context embedded mathematical thinking to more abstract and formal kinds of mathematics. Gestures and speech are thus all combined in the construction of complex multi-layered and multimodal representations in which no single layer is complete or coherent on its own.

In this paper, I concur with the notion that the simultaneous use of gestures and verbal communication benefits the teaching of mathematics. It is therefore important that the appropriate use of gestures be recognized as a legitimate teaching strategy that supports good teaching, and I argue that for gestures to be meaningful they should be used strategically (Chikiwa \& Schäfer, 2019). Studying the use of gestures in multilingual classes is crucial because gestures can serve as important support mechanisms to teachers who teach in a language that is not their first, and thus have a low proficiency in the LOLT. Gestures can also provide supporting backup for teachers who find themselves in situations where they lack proficiency in the language of their learners and are not familiar with the associated 
syntax, pronunciation and intonation practices and routines of that language.

\section{Classification of Gestures}

Although gestures have been classified in many ways in the research literature (see Cienki \& Müller, 2008; Ekman \& Friesen, 1974; Kendon, 2004; Lim, 2019; Scherer \& Ekman, 1982), in this paper I adopted McNeill (1992)'s classification of four types of hand gestures, that is iconic, metaphoric, deictic and beat gestures. Iconic gestures are hand movements used to create a picture or present images of concrete entities and/or actions. McNeill (2005) elaborates further referring to iconic gestures as hand gestures that represent meaning closely related to the semantic content sections of speech that they accompany. Iconic gestures draw their communicative power from being perceptually similar to the event or concept under discussion (McNeill, 1992). Iconic gestures can be subcategorised into the following as found in literature:

Action gestures are gestures that occur when the arms or hands mimic an observable physical act performed by an organism (Arzarello et al., 2009; Edwards, 2009; McNeill, 2005). An example is when showing a water wave motion;

Magnitude gestures occurs when the hands are used to represent a large or small distance, size, or amount of some phenomenon (McNeil, 1992);

Movement gestures are those produced when the hands are used to represent an observable entity or entities going from one point to another, with a relative emphasis on direction, speed, or spatial position of the entity's (entities') starting point relative to its (their) ending point (Kendon, 2004) (e.g., using a hand to represent the revolution of the earth around the sun);

Shape gestures are hand gestures that indicate the physical outline of a form or figure (e.g., a circle) (Kendon, 2004; McNeil, 1992);

Spatial position gestures are hand gestures that one may use to indicate an observable entity placed in a specific location relative to another observable entity (Arzarello et al., 2009; Gibson, 2014).

In another study, Edwards (2009) extended McNeill's iconic classification to include iconic-physical gestures (those gestures resembling physical phenomenon) and iconic-symbolic gestures (those referring to mathematical symbols). In another study, Arzarello and Robutti (2004) used iconic-symbolic gestures as well in a similar way to Edwards (2009), but they further extended the categorisation to include iconicrepresentational gestures which are gestures related to graphic representations of concepts in mathematics.

Metaphoric gestures indicate a pictorial representation of an abstract mathematical idea that cannot be represented physically.
The third group is deictic (pointing) gestures, which are those used to point to or refer to objects, locations, inscriptions, or people with fingers or hands, directing the listener's attention to these objects. Cochet and Vauclair (2014, p. 279) state that "deictic gestures are produced to direct a recipient's attention towards a specific referent in the proximal or distal environment." Deictic gestures are context dependent, pointing at a concrete item, indicating directions, referring to the past or abstract loci in space (Alibali et al., 2013).

The last group is beat gestures, which are short, rapid and repeated hand movements that follow the rhythm or beat of the speech. These types of gestures may be considered as manual gestures which do not have a clear referential component. They are mainly to enrich conversations.

While this classification by McNeill formed the basis of my analysis, some other gestures emerged from the teachers' actions during their teaching.

\section{THEORETICAL FRAMEWORK}

This study is guided by two theories the embodied cognition theory and dual coding theory.

\section{Embodied Cognition Theory}

First theory informing this study is the embodied cognition theory which takes the position that our bodily actions (gestures) are not only integral to our being (and teaching), but are inseparable (Clark, 2008; Shapiro, 2014). From an embodied cognition perspective, humans are organisms whose bodies and minds form an integrated and intertwined system which is inseparable from the environment (Thompson, 2010). Humans are thus active agents rather than disembodied reactors to arbitrary stimuli.

Embodied cognition is based on the idea that the body, mind, and environment are inseparably connected. Embodied cognition theory posits that the mind is not only connected to the body but that the body influences the mind and cognitive processes are deeply rooted in the body's interactions with the world (Wilson, 2002). A growing body of evidence suggests that language evolved from manual gestures by an individual, gradually incorporating motor acts with vocal elements (De Stefani \& De Marco, 2019). As argued by Gibson (2014) and Wilson (2002), human cognition is thus rooted in the two-way intuitive and physical interactions of the body with the world around an individual. While authors associate embodied cognition with the metaphor of grounding (Alibali \& Nathan, 2012; Barsalou, 2008), other researchers argue that the best way to articulate the embodied cognitive theory is to specify the nature of the dependence of cognition on the body (Clark, 2008; Shapiro, 2014; Wilson, 2002). When viewed in this manner the theory prompts one to investigate the significant roles that the body and verbal 
language play in cognition. The embodied approaches to language use in teaching propose that conceptual knowledge and understanding is grounded in the correct use of body experience together with verbal communication and in the sensorimotor systems (Barsalou, 2008) that are involved in forming and retrieving semantic knowledge.

This theory is relevant to this study because it views the teacher's body in the teaching process as inseparable from the mind. The theory also emphasizes the role played by external environments in the cognitive processes positing that our physical interaction with the world around us influences our cognitions (Shapiro, 2014). Tran, Smith and Buschkuehl (2017) argue that before abstract forms of mathematical thoughts emerged, problem solving in the real world already required movement through space and manipulating real objects. During teaching, this thus provides a "... natural desire to situate cognition with real contexts in reflecting the mind-body connections of mathematical concepts" (Tran et al., 2017, p. 3).

\section{Dual Coding Theory}

The Dual Coding Theory (DCT) is founded on the premises that "information for memory is processed and stored by two interconnected systems and sets of code," also known as the verbal or spoken and nonverbal (visual) systems (Paivio, 2006; Suh \& Moyer-Packenham, 2007). Dual coding theory advocates for the use of both verbal (spoken) and non-verbal (visuals) cues in teaching to enhance teaching and understanding. In this study, the teacher's use of gestures provides the visual code while the spoken language in LOLT and the learners' first language provides the verbal code. As argued by Mayer and Anderson (1991, p. 485), DCT “... predicts that learners will remember and transfer material better if they encode the material both visually and verbally because they have two separate ways of finding the information in memory." Teachers' over reliance on one mode of presenting subject content to the learners may not yield intended results since some learners are visually inclined while others are verbally inclined.

According to the DCT, the two codes (verbal and visual) are interdependent and complement each other in the teaching and learning environment. When used concurrently during teaching, gestural codes (visual) and the spoken language (verbal codes) produce better results than when only one code is used (Paivio, 2006). The challenge to be overcome, however, is the less attention gestures as visual codes may be given over use of the verbal code by teachers especially of multilingual classes.

In this study, the combination of embodied cognition theory and DCT was motivated by a strong relationship that exists between them, and also that they complement each other. Embodied cognition theory argues that teacher gestures (the visual code) influence learners' construction of mental representations of mathematical concepts when appropriately used with spoken language (Chu \& Kita, 2011; Tran et al., 2017). When mathematics is viewed as an embodied, socially constructed human activity through the dual coding process, physical gestures as used by teachers are neither a by-product to cognition, nor irrelevant to communication. Instead, gesture as they provide the visual element, may thus constitute a particular modality of embodied cognition, and together with oral speech, it can serve as a window on how teachers talk about mathematics during instruction in multilingual classes.

\section{METHODOLOGY}

The data for this qualitative case study is comprised of a set of gestures displayed by two selected teachers (A and B) of multilingual mathematics classes while teaching trigonometry in secondary schools. The participants were qualified high school teachers who are isiXhosa first language speakers who were videotaped while teaching trigonometry to grade 11 classes in the Eastern Cape province of South Africa. The two teachers were purposively selected on the basis that they were willing to participate, they were isiXhosa first language speakers and teaching grade 11 mathematics. Participants in this study did so voluntarily. The teachers' consent to participating in this study and to have their lessons and interviews recorded was sought prior to the study's commencement. All ethical protocols were observed. The lessons were video recorded with the camera focusing only on the teacher. This was to capture all teacher language practices together with the associated gestures for analysis at the later stage.

At the end of the five lessons, each teacher was interviewed once for about an hour. I worked and read through video recordings and transcriptions and noted the nature of gestures made by the selected teachers, as well as their similarities and differences. I sent back the transcriptions together with the videos to the participants to verify if these transcriptions were a correct record of what transpired during their teaching. Thee data was analysed qualitatively. The gestures used by these teachers were isolated and identified. An analytical framework using McNeill's (1992) classification of gestures (iconic, pointing, metaphoric and beat) was used to categorize the teachers' gestures. Excerpts presented in the analysis were chosen on the basis that they will be able to show clearly teachers' use of verbal language in English and isiXhosa together with gestures. While gestures were present even when the teacher was speaking in LOLT only, I focused only on those sections when both languages were used. While McNeill's (1992) classification formed an entry point to 
data analysis, other gestures were also evident during the analysis and were noted and included in the analysis.

\section{FINDINGS}

This study's focus was two-fold, first to look at forms of gestures teachers of multilingual mathematics classes use during teaching; and second to find out how teachers of multilingual mathematics classes utilize learners' home language, language of learning and teaching (LOLT, ) and gestures to foster understanding in the teaching of mathematics. Teachers in this study used mainly the iconic gestures and its various subcategorization as presented above. These gestures were used in conjunction with the learners' first language (isiXhosa) during teaching. In the interview, Teacher B mentioned, "use of hands and isiXhosa or any language, comes naturally because you want to point to key aspects of teaching and learning". Teacher A said, "In some of my lessons as you can see I had to trace the trigonometric graphs in the air with my figure to remind them of the basic shapes of the graph". Teachers used a combination of verbal and gestural expressions in their multilingual classes (see Excerpts 1 to 6). This allowed these teachers to show their visualization of concepts, diagrams and other representations of trigonometry concepts more explicitly during teaching. Teachers in this study concurred that the use of iconic and pointing gestures helped to ground what was being discussed in the immediate environment. This was noted from what they said during interviews: "Pointing to the diagrams on the chalkboard and constantly referring to the included angles and corresponding sides helped my learners to actually relate what I was saying to the corresponding object" (Teacher B). Teacher A reiterated that "the drawings helped me as I could always point to the aspect I wanted my learners to focus on at any time during my lessons. I also used isiXhosa for them to understand better." Thus, the simultaneous use of gestures and verbal communication in both isiXhosa and the LOLT was seen as of benefit to teaching of trigonometry in these multilingual classes.

Teacher A in Excerpt 1 was able to, first, point to the angle in question (see Excerpt 1a) \&d)) using deictic gestures. Teacher A was directing learners' attention towards a specific referent angle in his proximal or distal environment (Cochet \& Vauclair (2014). Secondly, the teacher illustrated the included angle and related sides using his hands (iconic-symbolic gesture) during the discussion of the area rule (see Excerpts 1b, 1c, \& 1e). Iconic hand gestures, mainly those showing the shape (see Excerpt 1c), movement (see Excerpt 1e, \& 1f) and action (see Excerpt 1b, \& 1e) were used by Teacher $A$ to provide a representation of an included angle. In doing

Excerpt 1. Teacher A's gestures and verbal language

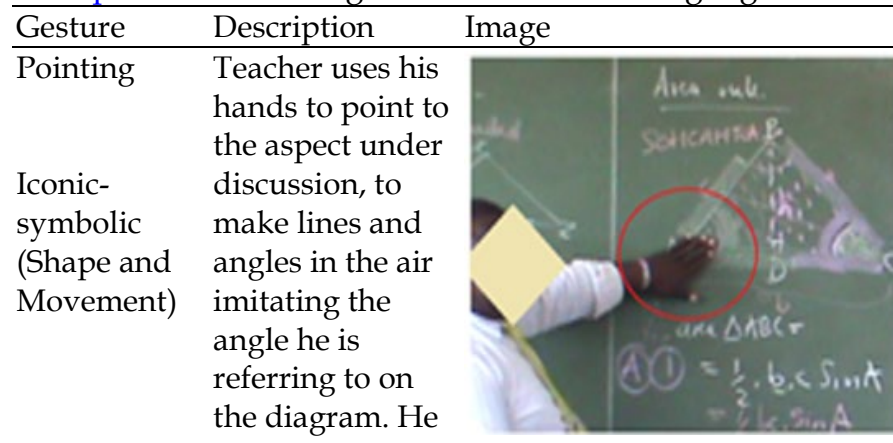

(a)

does this while

speaking in isiXhosa. The hands were also moved to show referent sides.

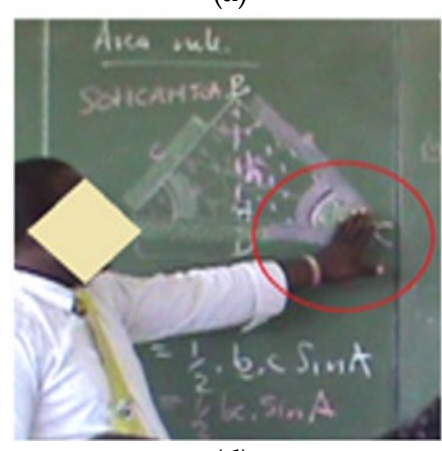

(d)

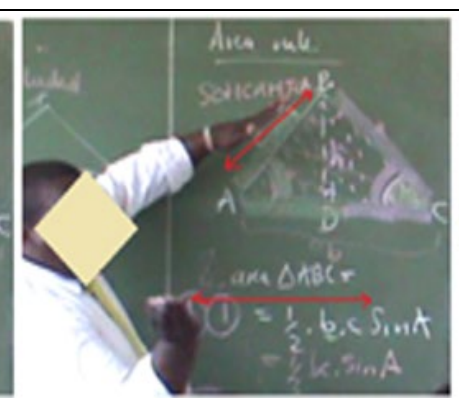

(b)

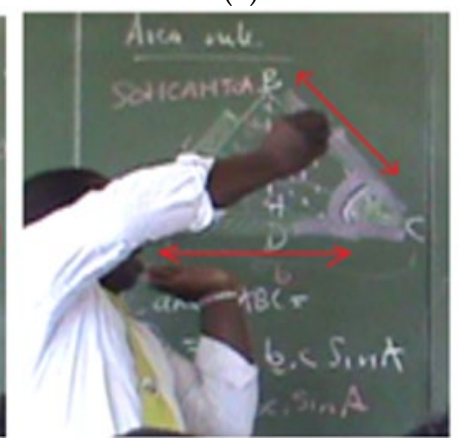

(e)

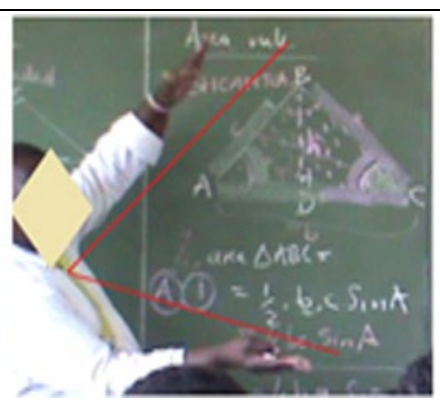

(c)

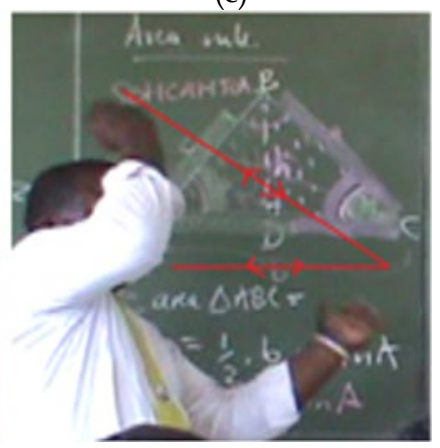

(f)

Teacher A's words during teaching

Nantsi i-clue ukuba ndi sebenza ngo-angle (Here is a clue when working with angle A). [Pointing at angle A, see a)]

Jonga, zeziphi i-sides endizinidayo? Ngu-c nabani? No-b. (Look, which sides do I need to consider? Its $c$ and what? And $b$.) [teacher moves both his hands along $\mathrm{AB}$ and $\mathrm{BC}$, see $\mathrm{b}$ ) and $\mathrm{c}$ )]

Uba ndisebenza ngo- angle C, ngubani endimnidayo? Ngu-a, nabani? No-b. Ubandisebenza ngo-angle B, ngubani endimnidayo? (If I use angle $\mathrm{C}$, which sides do I need to consider? It is " $a$ " and which side? And " $b$ ". If I use angle B, which sides do I need to consider)? [Teacher moves both his hands along $\mathrm{AB}$ and $\mathrm{BC}$, see e) and $\mathrm{f}$ )] [chorus answer from the learners] a..... [teacher points at a learner. The learner responds A and C] 
this, he used hand movements as they formed the shape of an included angle (see Excerpt 1 b, 1c, 1e, \& 1f). The teacher's intention was to engage his learners in understanding the area rule informally before stating it as a formula. While doing all these gestures, both isiXhosa and English (the LOLT) were used simultaneously by this teacher. In some cases, the whole sentence except for a few borrowed English terms was in isiXhosa. For example: Uba ndisebenza ngo- angle C, ngubani endimnidayo? Ngu-a, nabani? No-b. Ubandisebenza ngo-angle $B$, ngubani endimnidayo? (If I use angle $C$, which sides do I need to consider? It is " $a$ " and which side? And " $b$ ". If I use angle B, which sides do I need to consider)? During interviews, Teacher A mentioned that "At times one has to use a language that learners understand or else you will be talking to yourself. Pointing and showing exactly what you are referring to in very very important so that as a teacher, I am moving together with my learners." The use of learners' first language together with gestures was seen by Teacher A as unavoidable but a necessary teaching tool for enhancing understanding.

When explaining the concept of an included angle, Teacher A used his fingers to point, and refer to the diagrams (see Excerpt 2a, 2b, \& 2e) he was working with. $\mathrm{He}$ also used the following words to accompany his gestural actions: Ndinikwe eli side neli side nale- angle and aku specifayiwanga, akuthwanga phaya an included angle, $k u$ thwe two sides and an angle. (I'm given this side and this side, and this angle it has not been specified it is and included angle, it just says two sides and an angle). As indicated by Alibali et al. (2013), deictic gestures are context dependent, pointing at a concrete item to indicate a referent point or directions related to the point under discussion. Teacher A use isiXhosa terms like eli, neli, nale as he was pointing to the referent sides in that question. Metaphoric gestures were not used

Excerpt 2. Teacher A's gestures and verbal language

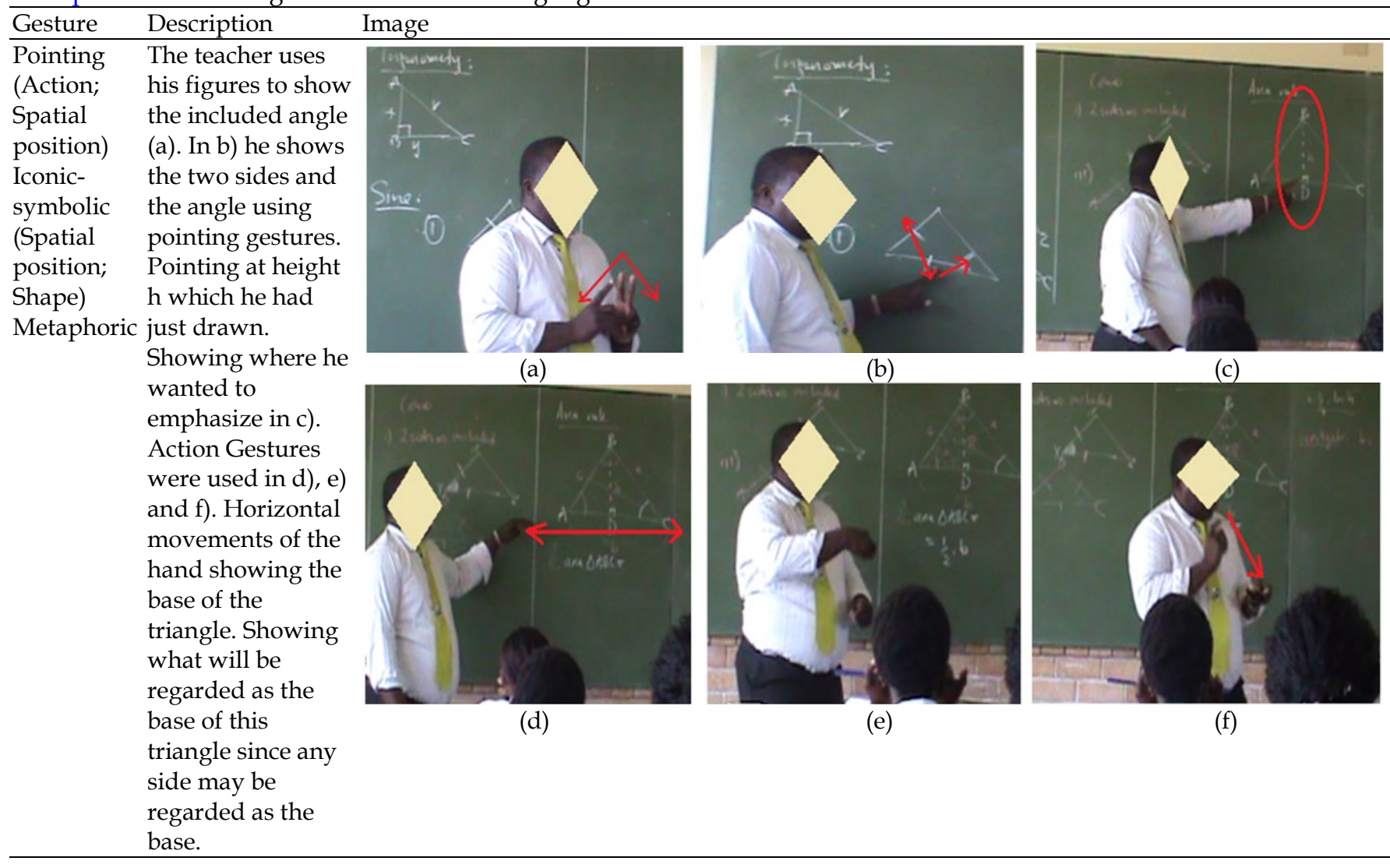

\footnotetext{
Teacher A's words during teaching

Nanku mzekelo i-condition yokuqala ndine right angle triangle, nantsi triangle yam (Here is an example, the first condition is that I have a right angle triangle, here is my triangle) [the teacher draws the triangle]

Ndinikwe eli side neli side nale- angle and aku specifayiwanga, akuthwanga phaya an included angle, kuthwe two sides and an angle. (I'm given this side and this side, and this angle it has not been specified it is and included angle, it just says two sides and an angle)

For i-area rule, masikhangele Sithe ukubangaba ndino triangle ABC ndibe ne le-height, mhlambe le height ndiyiphi gama, ndithi $n g u$ " $h$ " $n e h$ (For the area rule, let's look we said if I have triangle ABC and I also have this height let's say I give this height a name and call it " $\mathrm{h}$ " right)? [in in this teacher was pointing to the shape on the chalkboard and the specific sections of reference] Kule triangle $A B C, I$ know ukubangaba lona ngu angle $C$, this side will be side c. Ubangaba this is B, icala lonke leli ngu " $b$ ". Y $i$ base ke mos? So, $\boldsymbol{i}$ base ayingo " $d^{\prime}$, but $n g u$ - " $b$ " (In this triangle ABC I know that if this is angle C, this is side $c$ this is the base. If this is $B$, this whole side is " $b$ ". That is the base right? So, the base is not $D$, it is " $b$ "). [in d), e) and f), the teacher use pointing and illustrating gestures]
} 
Excerpt 3. Teacher A's gestures and verbal language

\begin{tabular}{ll}
\hline Gesture & Description \\
\hline Pointing & Pointing Gesture \\
& Uphi u a wethu? \\
& Teacher shows the \\
Iconic & side being refered \\
& to. He did the same \\
& with the written \\
& expression on the \\
& second diagram. \\
& Teacher uses hand \\
& gestures to clear \\
& some
\end{tabular}

misconceptions that

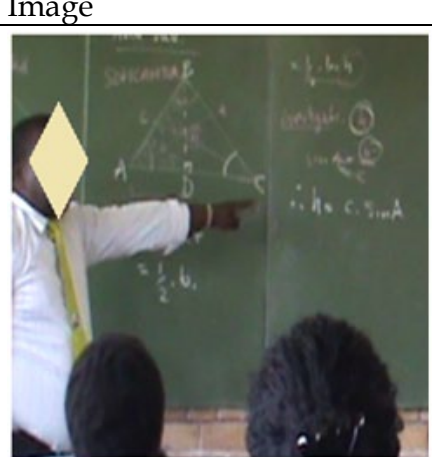

may arise. Here he is linking the variables $a$ and $b$, and the angle $\mathrm{C}$ in the formula to the diagram. Teacher showing and emphasizing the three trig ratios. The teacher uses his hands to give options from which learners are to choose from- sin cos, tan

(a)

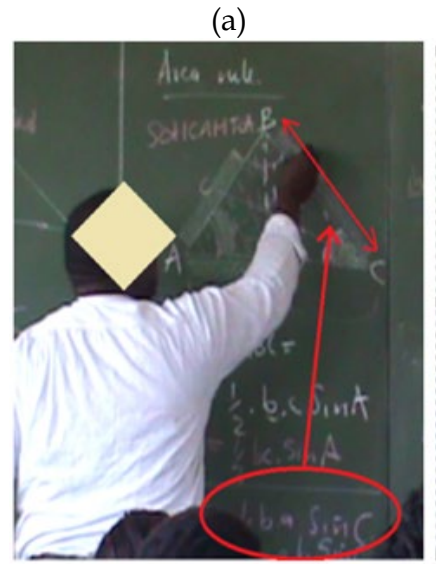

(d)

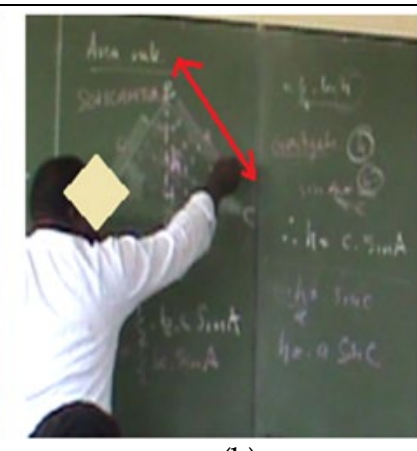

(b)

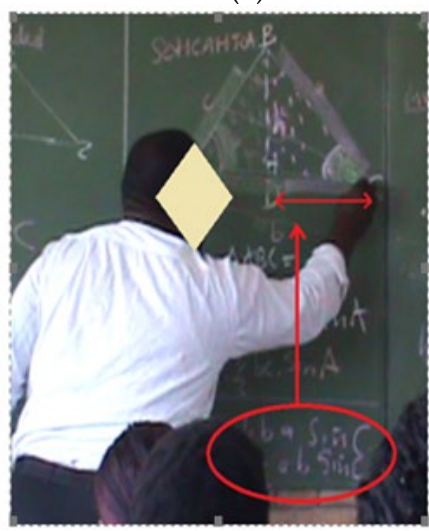

(e)

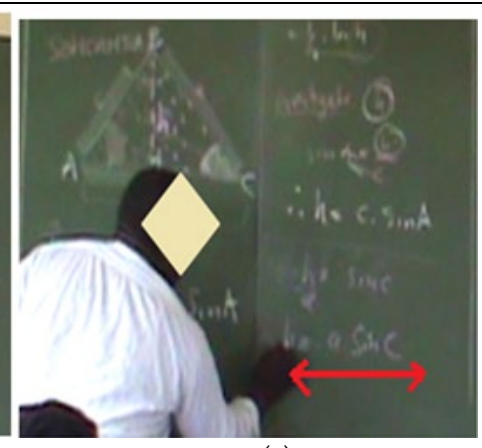

(c)

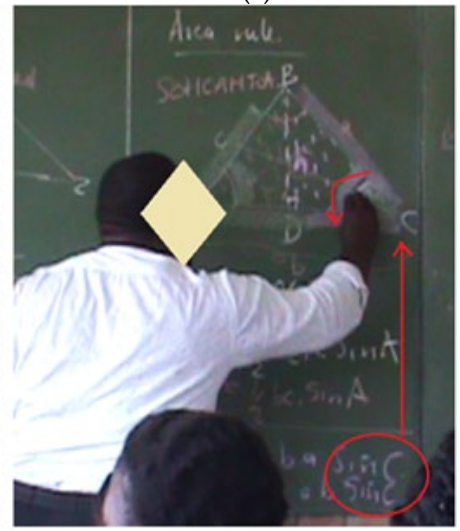

(f)

Teacher A's words during teaching

Isiphinto ethi kengoku uba sifunu " $h$ " as the subject of the formula. Jonga, siza cross multiplier akunjalo? Ekuqhibeleni $u$ " $h$ " will be $H=c$. $\sin A$. Can you see now? That represents kanye le value ka " $h$ ". Apha ngoku asisabhali " $h$ " si za bhala bani, ngubani $u$ " $h$ " wethu ngoku? Ngu c.Sin A (This gives us the direction that if we are looking for h as the subject of formula. Look we will cross-multiply isn't it? In the end $h=c$.sin A. That represents precisely the value of $h$. In this slot we no longer write " $h$ " what do we write, what is our " $\mathrm{h}$ " now? It is c.sinA.)

Masikhangele, uphu " $a$ "wethu? Nanku! U side " $a$ " lona. Uphu side, that is side " $a$ " the second one. Remember there was " $b$ " which is the normal base is " $b$ ". But $u$ " $h$ " wethu ngu a.SinC. (Let us look, where is our "a"? Here is it. This is side "a" the second one. But our h is a.sinC)

Uphi $u$ " $a$ " lo " $b$ "? There is " $a$ " and " $b$ " and nantsi angle yethu. Now, sisebenze ngo angle A, sa sebenza ngo angle $C$. What will be the correct formula for, if you use angle B? Khakucinge, sisebenza ngo angle bani? Ngo angle B 1/2.a.c.Sin B (Where is " $a$ " and " $b$ "? There is $a$ and $b$ and here is our angle. Now we have worked with angles A and C. Think about it, which angle are we dealing with? Its B hence $1 / 2$.a.c.Sin B)

extensively, however, they were evident in some of Teacher A's lessons for example in Excerpt 2e and $2 \mathrm{f}$.

Action Gestures were used in this lesson as shown in Excerpt 2d, 2e, and 2f. Teacher A employed horizontal movements of the hand when he was showing the base of the triangle. Showing what will be regarded as the base of this triangle since any side may be regarded as the base. Iconic representation was evidenced in this case by Teacher A. This was through multiple modes of representation (see Excerpts 1, 2, \& 3) that included various gestures, verbal communication in English and isiXhosa, and through diagrams that were either on the chalkboard or the projected screen. This was the case for all the observed teachers in this study (see Excerpt 4 \& 6). They drew diagrams on the chalkboard or on the projected screen, they used gestures (pointing, shape, movement, tracing, iconic) and they used verbal language in both isiXhosa and English. IsiXhosa words such as jonga (look), siyabona sonke (can we all see), siyayibona kwi-diagram (can we see on this diagram) masikhangela lapha (when we look here) (see Excerpts 1, 3, 4, \& 6) among others were used to draw learners' attention to the part of the diagram or writing on the chalkboard that they were focusing on together with deictic gestures. Teacher B during interviews argued: "I use isiXhosa and pointing using my fingers because I believe this is better than just talking without gesturing. Also, I can't just gesture alone because it will be like sign language. Moreover, in my day to day life I talk and gesture at the same time. My learners they do the same both in and outside school. So, it's natural for me to speak English and Xhosa and gesture at the same time." Teacher B explains that use of gestures and both languages was socially acceptable in his 
Excerpt 4. Teacher B's gestures and verbal language

\begin{tabular}{ll}
\hline Gesture & Description \\
\hline Pointing & $\begin{array}{l}\text { Using a finger to } \\
\text { point into the past } \\
\text { and asking } \\
\text { learners if they still } \\
\text { remember. }\end{array}$ \\
$\begin{array}{ll}\text { Iconic } & \text { Movement } \\
\text { Teacher used } \\
\text { and Spatial } \\
\text { position) }\end{array}$ & $\begin{array}{l}\text { pointing gestures } \\
\text { to repeat in }\end{array}$
\end{tabular}

isiXhosa

information

previously

presented in

English. This was

to emphasis

certain concepts.

The two

quadrants- Double gesture- pointing and showing (see f.)

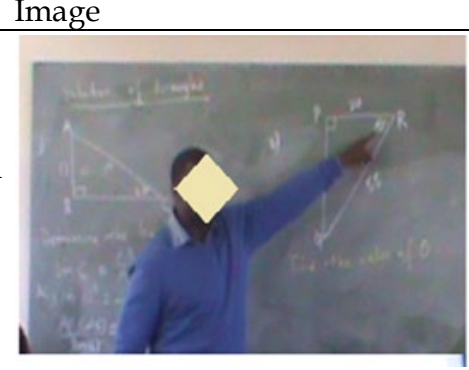

(a)

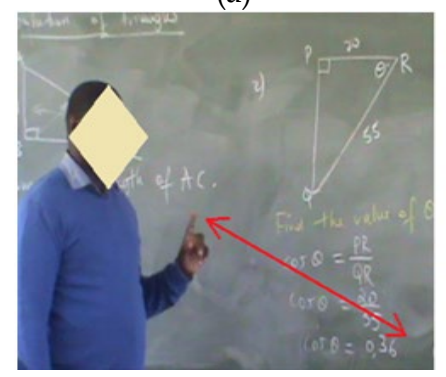

(d)

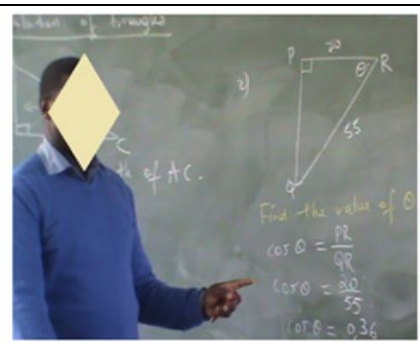

(b)

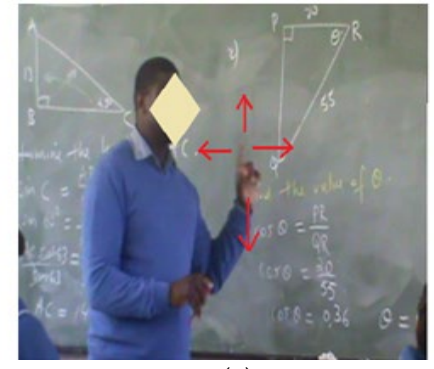

(e)

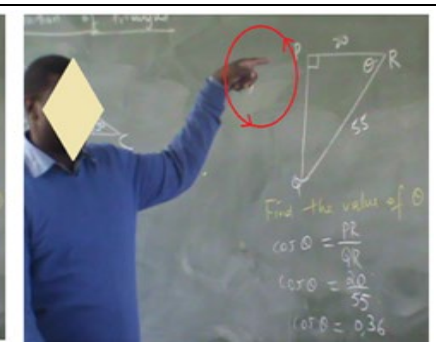

(c)

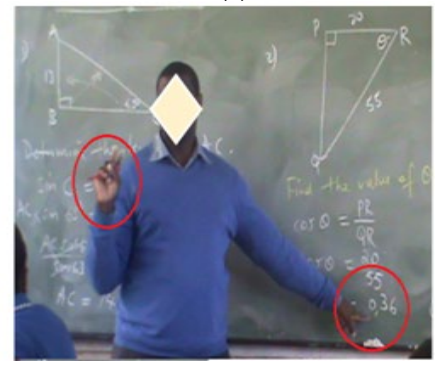

(f)

Teacher B's words during teaching

Sifuna bani, u- $\theta$ nhe? Sinikwe u-PR no-RQ isn't that so? u-PR uyintoni ku-a phaya? u-PR uyintoni ku- $\theta$ phaya? So kule one ratio that involves $i$-adjacent ne-hypotenuse, yeyiphi ratio siifunayo? (What do want, $\theta$ right? We are given $P R$ and $R Q$, isn't that so? What is PR there? So there is only one ratio involving the adjacent and hypotenuse, what is that ration we need?)

Usakhumbula how to find $\theta$ ? soyenza njani? Usakhumbula ngokuya besisenza i-ratios nhe, good, find $\theta$ ? (Do you remember how to find $a$ ? How do we do it? You remember when we were doing ratios right, good, find $\theta$ ) [Teacher used his finger to point in the past, see $b$ ) above.]

Mamela ke nantsi enyinto ebalulekileyo apha, siyevana. Jonga u-Cos $\theta$ here, $\operatorname{Cos} \theta$ i-positive and kule-quadrants where Cos is positive. Which are those two quadrants? I-quadrant and le-fourth quadrant isn't that so. (Listen up, something else that is important here. Look at $\operatorname{Cos} \theta$ here, $\operatorname{Cos} \theta$ i-positive and there are two quadrants where $\operatorname{Cos}$ is positive. Which are those two quadrants? The first quadrant and the fourth quadrant isn't that so. [Teacher points to the diagram and the workings on the chalkboard]

community and widely practiced. This thus encouraged him to use these tools for teaching purposes. Teachers in this study were thus observed making efforts to ground the trigonometric concepts in the classroom environment through some 'socially mediated' cognition (Hutchins, 1995).

While pointing gestures were prevalent in all teachers' lessons for grounding purposes (see Excerpts 1 to 6), iconic-representational gestures were also noted in these teachers' classes. Teacher B used iconic gestures in form of movement and spatial position as is shown in Excerpt 4 and 5. Teacher B used also deictic (pointing) gestures, where he pointed to or to objects and locations that were in the past using his fingers and hands. An example is when he said: Usakhumbula how to find $\theta$ ? soyenza njani? Usakhumbula ngokuya besisenza i-ratios nhe, good, find $\theta$ ? (Do you remember how to find a? How do we do it? You remember when we were doing ratios right, good, find $\theta$ ) While saying these words, Teacher B used his finger to point in the past (see Excerpt $4 \mathrm{~b}$ ). Here he was directing his learner's attention to those objects in the past lessons that they had dealt with. In fact, he was attempting to aid their memory using words and gestures.
It was common for teachers to trace diagrams of certain mathematical concepts for example angles (see Excerpt 1c \& 2a), triangles (Excerpt 4a \& 6b), height (Excerpt 2e), adjacent side (Excerpts $3 b$ to $3 e$ ) among others. I considered these iconic gestures as providing visual resemblances with the trigonometric concepts they were targeting to represent. This was also noted in Teacher B's lessons (see Excerpts 4 to 6). Use of iconic gestures in their various forms was considered to have a narrative function in this particular case.

As was done by Teacher A, in his lessons, Teacher be also used a lot of pointing gestures (see Excerpt 6) to direct learners to key referents that were necessary during class discussions. When emphasizing the sine ratio that involves opposite and hypotenuse, Teacher $B$ used a lot of deictic gestures while at the same time speaking in both the LOLT and isiXhosa. For example, he said: Kwenzakalani between icala leli le- angle C? Sawufuna i-ratio ethini e-involver i-opposite nantoni nehypotenuse. There is one ratio e-involver $i$-opposite nehypotenuse akunjalo? (What is happening between this angle and angle C? We will find the ratio that involves the opposite and hypotenuse. There is one ratio that involves the opposite and hypotenuse, isn't that so?) During this process, the Teacher traced with his finger 
Excerpt 5. Teacher B's gestures and verbal language

\begin{tabular}{|c|c|}
\hline Gesture & Description \\
\hline Pointing and & Using a finger \\
\hline Illustrating & to point to the \\
\hline & object being \\
\hline & referred to. \\
\hline & Teacher used \\
\hline & hand movement \\
\hline & and fingers to \\
\hline & $\begin{array}{l}\text { help learners } \\
\text { remember types }\end{array}$ \\
\hline & $\begin{array}{l}\text { of angles. } \\
\text { lon }\end{array}$ \\
\hline
\end{tabular}

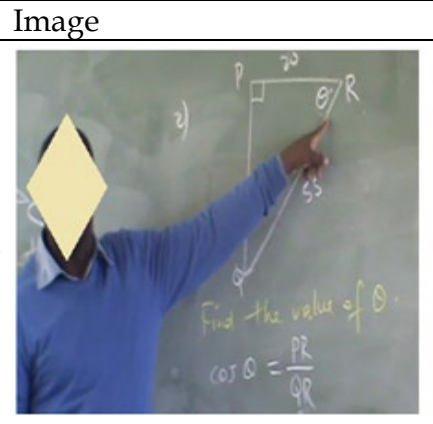

(a)

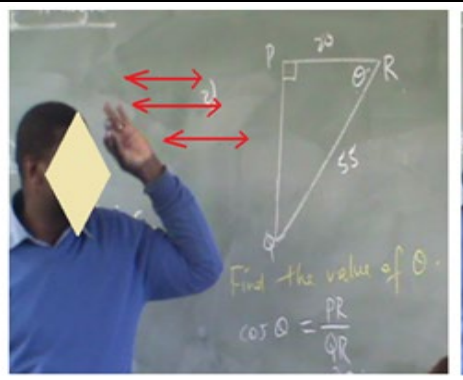

(b)

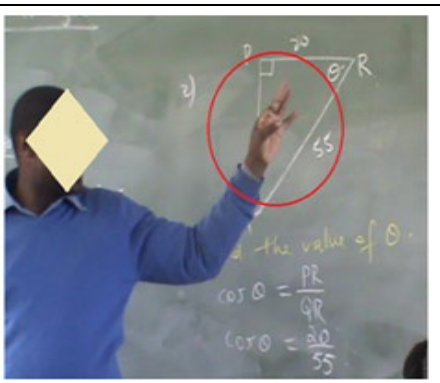

(c)

Teacher B's words during teaching

Sile three types of $i$-angles zethu. I-acute, le-obtuse and i-reflex, siyakumbula? Now jonga ku- $\theta$, is it acute or reflex or obtuse? I-angle enjani laphaya? (We have three types of our angles. Acute, obtuse and reflex, do you remember? Now look at $\theta$, is it acute, obtuse or reflex? What kind of an angle is it there?) [Teacher uses hand movements to show the angle being referred to.]

Excerpt 6. Teacher B's gestures and verbal language

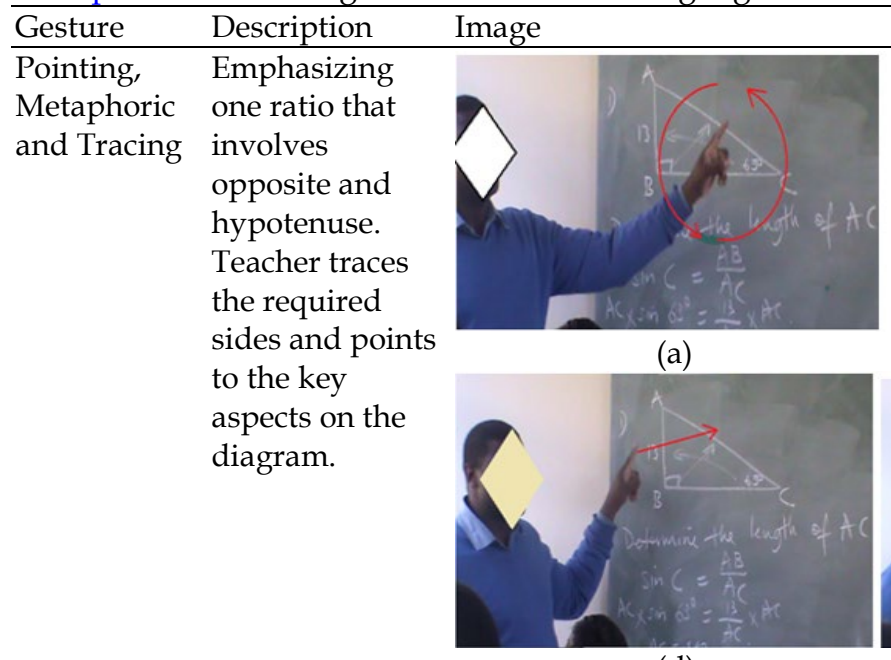

(d)

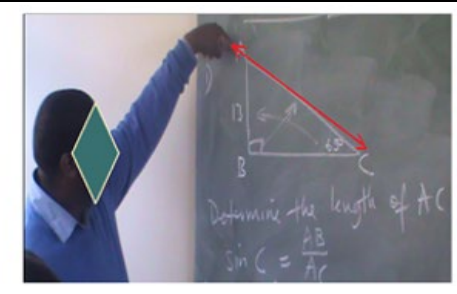

(b)

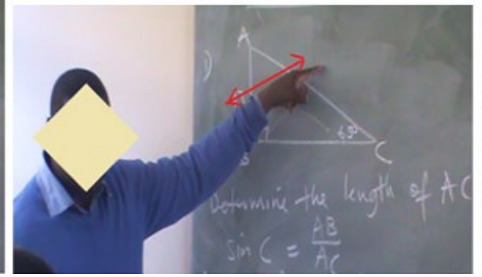

(e)

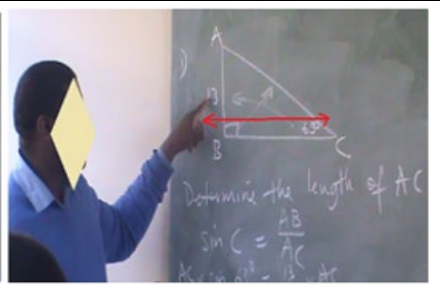

(c)

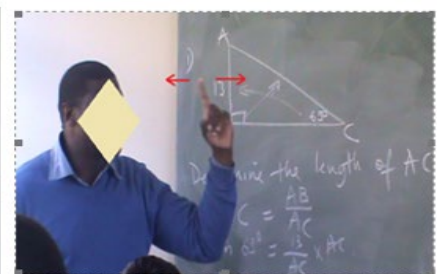

(f)

Teacher B's words during teaching

Apha sifuna bani? U-AC akunjalo? So u-AC, uyintoni phaya? I-hypotenuse siyabona? (What are we looking for here? AC isn't so? What is AC there? It is the hypotenuse, can you see?)

Kwenzakalani between icala leli le- angle C? Icala leli i-opposite nhe? Sawufuna i-ratio ethini e-involver i-opposite nantoni ne-hypotenuse. There is one ratio e-involver i-opposite ne-hypotenuse akunjalo? (What is happening between this angle and angle C? this side is opposite, right? We will find the ratio that involves the opposite and hypotenuse. There is one ratio that involves the opposite and hypotenuse, isn't that so?)

the required sides and points to the key aspects on the diagram as he used phrases such as icala leli. These can also be referred to as manifestations of metaphoric gestures (see Excerpt 6b, 6c, 6d \& 6e) where Teacher B was trying to make abstract ideas hypotenuse, adjacent and opposite as used in trigonometry more literal and concrete in form.

In this study, I noted that both teachers repeated their questions and explanations previously stated in one language (English) as they code switched to another language (isiXhosa). Accompanying gestures were often repeated as well. Common gestures across the observed teachers were the iconic and deictic. Metaphoric were less evident in the lessons presented by both teachers. Beat gestures were not evident across the observed teachers. Common subcategories of iconic gestures were action gestures, movement gestures and shape gestures. Spatial position and magnitude gestures were not very evident.

\section{DISCUSSION AND CONCLUSION}

The multilingual mathematics classroom should be as flexible as possible in terms of language and various visual tools used when teaching, to enable and enhance understanding of mathematics. In this study, the two teachers predominantly used deictic (pointing) and iconic gestures during teaching. This seemingly was used to link the teacher's verbal language and the diagrams on the chalkboard or what was previously learnt, which according to Clough and Hilverman (2018), serves to ground cognition into the physical 
environment. This prevalence of both deictic and iconic gestures could be as a result of what Valenzeno, Alibali, and Klatzky (2003) stressed, that "pointing and tracing gestures "ground" teachers' speech by linking abstract, verbal utterances to the concrete, physical environment" (p. 187).

While other forms of gestures where used, they were not as prevalent. Other forms of gestures such as the magnitude, direction and action gestures were used by the teachers to direct attention to the features of the problem. Teachers also used gestures to signal relevant information during teaching and to create objects in space using their fingers. Though in differing proportions, various types of gestures were observed as performed by teachers in this study. Teachers used gestures to ground trigonometry concepts to objects that were familiar to learners. Tran et al., $(2017$, p. 3) argues that "integrating the body into the [teaching and] learning experience can, therefore, improve mathematical understanding by providing a connection between concrete referents and abstract concepts."

Metaphoric gestures were not prevalent across the two teachers' lessons. As metaphoric gestures indicate a pictorial representation of abstract concepts of mathematical ideas that cannot be represented physically (McNeill, 2005), observed teachers were able to represent most of the concepts diagrammatically before using gestures. This could be the reason why metaphoric gestures were less evident. However, the teachers I observed in this study did not use beat gestures during their lessons. One may thus question whether gestures and their types vary with mathematical domains or whether prevalent of gestures by a teacher is related to personality, gender or whether one is trained to do so or not.

In literature, there is a lot of evidence that various aspects of mathematics are embodied (Tran et al., 2017), for example the use of fingers and arms to make angles or shapes (Fischer \& Brugger, 2011) and in this study, to show adjacent sides, opposite sides, included angles among others. Such use of fingers is a manifestation of embodied cognition (Moeller et al., 2012). Thus, I posit that teachers in my study taught trigonometry as embodied trigonometry. The teachers argued that use of gestures, and code switching was phenomenon that occurs in their society. Hence, they argued that incorporating such a socially accepted and used tool for mediating teaching would help improve understanding of mathematics concepts.

The two-directional and reciprocal relation that occurred through for example iconic-representational gestures during the teacher's demonstration of an included angle was vital. This may be considered as a semiotic tool that was used to help learners to perceptually encode the idea of 'inclusion' because of the two adjacent side. The pointing gestures directed at specific angles, sides of reference or other components on drawn diagrams during the teaching of the cosine rule may be considered as a way of guiding learners' perceptual encoding processes. While the policies on language use are silent on semiotics tools other than verbal language, teachers used gestures to enhance learning even though they had no training of how to use them and when to use them. This will help teachers avoid or minimize possible unwanted practices as gesture-speech mismatches especially in mathematics multilingual classes where learners are already struggling with the LOLT.

In this paper, I conclude that in multilingual classes all forms of teacher gestures that indicate and refers to objects and locations in reality may help improve learning. This was also concluded by Cook, Mitchell and Goldin-Meadow (2008) in monolingual settings that gestures referring to objects in physical referents make it easier for learners to link their developing mental representations to relevant parts of the external environment. This in turn makes teaching and learning real by grounding mathematical concepts in reality. Teachers in this study performed 'grounding' of concepts (Alibali \& Nathan, 2012) where they were mapping abstract trigonometry concepts to more concrete and familiar referents. I argue that such use of gestures facilitates meaning-making (Koedinger, Alibali, \& Nathan, 2008) during teaching.

I conclude that gestures and language (first language or LOLT) complement each other, and should be used as resources for mediating and scaffolding teaching and learning. They need to be thought of as a single system, larger than either language or gesture when considered separately (McNeill, 1992) during teaching of multilingual classes. It is thus important that language policies in South Africa such as LiEP and SALP acknowledge these resources and advise constructively on the strategic use of these in the mathematics classroom, particularly in the context of a multicultural and multilingual environment.

Funding: No funding source is reported for this study.

Declaration of interest: No conflict of interest is declared by author.

\section{REFERENCES}

Adler, J. (2001). Teaching Mathematics in Multilingual classrooms. Kluwer Academic Publisher.

Alibali, M. W., \& Nathan, M. J. (2012). Embodiment in mathematics teaching and learning: Evidence from learners' and teachers' gestures. Journal of the Learning Sciences, 21(2), 247-286. https:/ / doi.org/10.1080/10508406.2011.611446

Alibali, M. W., Nathan, M. J., Church, R. B., Wolfgram, M. S., Kim, S., \& Knuth, E. J. (2013). Teachers' gestures and speech in mathematics lessons: forging common ground by resolving trouble 
spots. ZDM Mathematics Education, 45, 425-440. https:/ / doi.org/10.1007/s11858-012-0476-0

Arzarello, F., \& Robutti, O. (2004). Approaching functions through motion experiments. Educational Studies in Mathematics 57(3), 305-308.

Arzarello, F., Paola, D., Robutti, O., \& Sabena, C. (2009). Gestures as semiotic resources in the mathematics classroom. Educational Studies in Mathematics, 70(2), 97-109. https://doi.org/10.1007/s10649-008-9163$\mathrm{Z}$

Auer, P. (1984). Bilingual conversation. Benjamins. https:// doi.org/10.1075/pb.v.8

Barsalou, L. W. (2008). Grounded cognition. Annual Review of Psychology, 59, 617-645. https://doi.org/ 10.1146/annurev.psych.59.103006.093639

Borodo, M. (2015). Multimodality, translation and comics. Perspectives: Studies in Translatology 23(1), 22-41. https:/ / doi.org/10.1080/0907676X.2013.876057

Canagarajah, S. (2011). Code meshing in Academic Writing: Identifying Teachable Strategies of Translanguaging. Modern Language Journal 95(3), 401-417. https:/ / doi.org/10.1111/j.1540-4781.2011. 01207.x

Chikiwa, C., \& Schäfer, M. (2019). Visualisation processes in mathematics classrooms- The case of gestures. In M. Graven, H. Venkat, A. A. Essien, \& P. Vale (Ed.), 43rd Annual Meeting of the International Group for the Psychology of Mathematics Education (vol. 4, pp. 4-24). Pretoria, South Africa: PME.

Chu, M., \& Kita, S. (2011). The nature of gestures' beneficial role in spatial problem solving. Journal of Experimental Psychology: General, 140(1), 102-116. https:// doi.org/10.1037/a0021790

Cienki, A., \& Müller, C. (2008). Metaphor and gesture. John Benjamins Publishing. https://doi.org/10.1075/ gs.3

Clark, A. (2008). Supersizing the mind: Embodiment, action, and cognitive extension. Oxford University Press. https:/ / doi.org/10.1093/acprof:oso/97801953332 13.001.0001

Clough, S., \& Hilverman, C. (2018). Hand gestures and how they help children learn. Frontiers for Young Minds, 6, 29. https://doi.org/10.3389/frym.2018. 00029

Cochet, H., \& Vauclair, J. (2014). Deictic gestures and symbolic gestures produced by adults in an experimental context: Hand shapes and hand preferences. Laterality: Asymmetries of Body, Brain and Cognition. Taylor and Francis, 19(3), 278301.

https: / / doi.org/10.1080/1357650X.2013.804079

Cook, S. W., Mitchell, Z., \& Goldin-Meadow, S. (2008). Gesturing makes learning last. Cognition, 106(2),
1047-1058. https://doi.org/10.1016/j.cognition. 2007.04.010

Creese, A., \& Blackledge, A. (2010). Translanguaging in the bilingual classroom a pedagogy for learning and teaching. The Modern Language Journal, 94, 103115. https://doi.org/10.1111/j.1540-4781.2009.00 986.x

Cummins, J. (2000). Language, power and pedagogy: Bilingual children in the crossfire. Multilingual Matters. https:/ / doi.org/10.21832/9781853596773

De Stefani, E., \& De Marco, D. (2019). Language, gesture, and emotional communication: An embodied view of social interaction. Frontiers in Psychology, 10, 2063. https:/ / doi.org/10.3389/fpsyg.2019.02063

Edwards, L. D. (2009). Gestures and conceptual integration in mathematical talk. Educational Studies in Mathematics, 70, 127-141. https://doi.org/ $10.1007 /$ s10649-008-9124-6

Ekman, P., \& Friesen, W. V. (1974). Detecting deception from the body or face. Journal of Personality and Social Psychology, 29(3), 288-298. https://doi.org/ $10.1037 /$ h0036006

Figone, K. E. (2012) The Hegemony of English in South African Education [Scripps senior theses]. Paper 43. http:/ / scholarship.claremont.edu/scripps_theses $/ 43$

Fischer, M. H., \& Brugger, P. (2011). When digits help digits: spatial-numerical associations point to finger counting as prime example of embodied cognition. Frontiers in Psychology, 2(260), 1-7. https: / / doi.org/10.3389/fpsyg.2011.00260

García, O. (2009). Bilingual education in the 21st century: A global perspective. Wiley-Blackwell.

Gibson, J. J. (2014). The ecological approach to visual perception: Classic edition. Taylor \& Francis. https:// doi.org/10.4324/9781315740218

Goldin-Meadow, S., \& Alibali, M. W. (2013). Gesture's role in speaking, learning, and creating language. Annual Review of Psychology, 64, 257-283. https:/ / doi.org/10.1146/annurev-psych-113011143802

Hare, A., \& Sinclair, N. (2015). Pointing in an undergraduate abstract algebra lecture: Interface between speaking and writing. Proceedings of PME39, 3, 33-40.

Ho, J. W. (2007). Code mixing: Linguistic form and sociocultural meaning. The International Journal of Language, Society and Culture, 21. www.educ.utas. edu.au/users/tle/JOURNAL/

Hutchins, E., \& Palen, L. (1997). Constructing meaning from space, gesture, and speech. In L. B. Resnick, R. Saljo, C. Pontecorvo, \& B. Burge (Eds.), Discourse, Tools, and Reasoning: Essays on Situated Cognition (pp. 23-40). Springer-Verlag. https://doi.org/ 10.1007/978-3-662-03362-3_2 
Kendon, A. (2004). Gesture: Visible action as utterance. Cambridge University Press. https://doi.org/ 10.1017/CBO9780511807572

Kotzé, T., Van der Westhuizen, M., \& Barnard, E. (2017). Teaching strategies to support isiXhosa learners who receive education in a second/third language. South African Journal of Education, 37(3), 1-12. https://doi.org/10.15700/saje.v37n3a1374

Li, W. (2017). Translanguaging as a practical theory of language. Applied Linguistics, 39(1), 9-30. https:/ / doi.org/10.1093/applin/amx039

Lim, F. V. (2019). Analyzing the teachers' use of gestures in the classroom: A systemic functional multimodal discourse analysis approach. Social Semiotics, 29(1), 83-111. https://doi.org/10.1080/10350330.2017.14 12168

Mayer, R. E., \& Anderson, R. B. (1991). Animations need narrations: An experimental test of a dual-coding hypothesis. Journal of Educational Psychology, 83, 484-490. https://doi.org/10.1037/0022-0663.83.4. 484

McNeill, D. (1992). Hand and mind: What gestures reveal about thought. University of Chicago Press.

McNeill, D. (2005). Gesture and thought. University of Chicago Press. https://doi.org/10.7208/chicago/ 9780226514642.001.0001

Mkhize, D., \& Balfour, R. J. (2017). Language rights in education in South Africa. South African Journal of Higher Education, 31(6), 133-150. https://doi.org/ 10.20853/31-6-1633

Moeller, K., Fischer, U., Link, T., Wasner, M., Huber, S., Cress, U., \& Nuerk, H.-C. (2012). Learning and development of embodied numerosity. Cognitive Processing, 13(1), 271-274. https://doi.org/10.1007 /s10339-012-0457-9

Paivio, A. (2006, September). Dual coding theory and education. In The Conference on Pathways to Literacy Achievement for High Poverty Children (pp. 1-20).

Probyn, M. (2009). Smuggling the vernacular into the classroom: Conflicts and tensions in classroom codeswitching in township/rural schools in South Africa. International Journal of Bilingual Education and Bilingualism, 12(2), 123-136. https://doi.org/ 10.1080/13670050802153137

Redlinger, W. E., \& Park, T. Z. (1980). Language mixing in young bilinguals. Journal of Child Language, 7(2), 337-352. https://doi.org/10.1017/S030500090000 $266 X$

Roth, W. M. (2002). Gestures: Their role in teaching and learning. Review of Educational Research, 71, 365-392. https:/ / doi.org/10.3102/00346543071003365
Sabena, C. (2018). Exploring the contribution of gestures to mathematical argumentation processes from a semiotic perspective. In G. Kaiser, H. Forgasz, M. Graven, A. Kuzniak, E. Simmt, \& B. Xu (Ed.), Invited Lectures from the 13th International Congress on Mathematical Education (pp. 541-559). Springer. https://doi.org/10.1007/978-3-319-72170-5_30

Scherer, K. R., \& Ekman, P. (Eds.). (1982). Handbook of methods in nonverbal behavior research. Cambridge University Press.

Setati, M. (2008). Access to mathematics versus access to the language of power: The struggle in multilingual classrooms. South African Journal of Education 28(1), 103-116.

Shapiro, L. (2014). Routledge handbook of embodied cognition. Routledge. https://doi.org/10.4324/ 9781315775845

Suh, J. M., \& Moyer-Packenham, P. S. (2007). The application of dual coding theory in multirepresentational virtual mathematics environments. In Proceedings of the 31st Conference of the International Group for the Psychology of Mathematics Education (Vol. 4, pp. 209-216). PME.

Thompson, E. (2010). Chapter 1: The enactive approach. In Mind in life: Biology, phenomenology, and the sciences of mind. Harvard University Press.

Tran, C., Smith, B., \& Buschkuehl, M. (2017). Support of mathematical thinking through embodied cognition: Nondigital and digital approaches. Cognitive Research: Principles and Implications, 2(16), 1-18. https:/ / doi.org/10.1186/s41235-017-0053-8

Valenzeno, L., Alibali, M. W., \& Klatzky, R. (2003). Teachers' gestures facilitate students' learning: A lesson in symmetry. Contemporary Educational Psychology, 28(2), 187-204. https://doi.org/10.1016 /S0361-476X(02)00007-3

Wilson, M. (2002). Six views of embodied cognition. Psyconomic Bullettin \& Review, 9(4), 625-636. https://doi.org/10.3758/BF03196322

Yoon, C., Thomas, M., \& Dreyfus, T. (2011). Grounded blends and mathematical gesture spaces: Developing mathematical understandings via gestures. Educational Studies in Mathematics, 78, 371393. https:/ / doi.org/10.1007/s10649-011-9329-y

Young, V. A., Barrett, R., Young-Rivera, Y., \& Lovejoy, K. B. (2014). Other people's English: Code-meshing, code-switching, and African-American literacy. Teachers College Press.

\section{http://www.ejmste.com}

